\title{
Complications with PMMA compared with other materials used in cranioplasty: a systematic review and meta-analysis
}

Rafaella de Souza LEÃO(a) Juliana Raposo Souto MAIOR(a) Cleidiel Aparecido de Araújo LEMOS ${ }^{(b)}$ Belmiro Cavalcanti do Egito VASCONCELOS(c)

Marcos Antônio Japiassú Resende MONTES(a)

Eduardo Piza PELLIZZER ${ }^{\text {(b) }}$ Sandra Lúcia Dantas de MORAES(a)

(a) Universidade de Pernambuco - UPE, Dentistry School, Recife, PE, Brazil.

(b) Universidade de Pernambuco - UPE, Dentistry School, Programs in Oral and Maxillofacial Surgery, Recife, PE, Brazil.

(c) Universidade Estadual Paulista - Unesp, School of Dentistry, Department of Dental Materials and Prosthodontics, Araçatuba, SP, Brazil.

Declaration of Interest: The authors certify that they have no commercial or associative interest that represents a conflict of interest in connection with the manuscript.

Corresponding Author:

Sandra Lúcia Dantas de Moraes

E-mail: sandra.moraes@upe.br

hitps://doi.org/10.1590/1807-3107bor-2018.vol32.0031

Submitted: August 15, 2017

Accepted for publication: February 20, 2018

Last revision: March 09, 2018

\begin{abstract}
Polymethyl methacrylate (PMMA) has been considered a suitable material for cranioplasty. However, no consensus has been reached concerning the best material for cranioplasty with regard to minimizing complications. Thus, this systematic review and meta-analysis aimed to compare the complication rates of PMMA with those of autologous bone and titanium mesh. This review was registered with PROSPERO (CRD42016042725). Systematic searches were conducted on PubMed/ MEDLINE, Scopus, and Web of Science. The focus question was, "Do PMMA prostheses used in cranioplasty have complications rates similar to those of autologous bone and titanium mesh?" A meta-analysis of complication rates was performed on the basis of dichotomous outcomes assessed by risk ratio (RR) with corresponding $95 \%$ confidence intervals (CI). From 1014 data sources, 11 articles were selected according to eligibility criteria. These articles involved 1,256 individuals and 1,278 cranioplasties using autologous bone $(n=408)$, PMMA $(n=379)$, or titanium $(n=151)$. The follow-up period ranged from 63 days to 54.3 months. No difference was observed between the complication rates of PMMA and autologous bone $(\mathrm{p}=0.94 ; \mathrm{RR}, 0.98 ; 95 \% \mathrm{CI}, 0.54-1.75)$ or between PMMA and titanium ( $\mathrm{p}=$ 0.38 ; RR, 1.59; 95\%CI, 0.57-4.48). Sub-analysis of the reasons for craniotomy (trauma/non-trauma) was conducted, which revealed no significant difference ( $p=0.91 ; R R, 0.95 ; 95 \% C I, 0.37-2.42)$. The meta-analysis indicated that the use of PMMA yields complication rates that are near those of autologous bone and titanium mesh.
\end{abstract}

Keywords: Acrylic Resins; Prosthesis Implantation; Skull.

\section{Introduction}

Craniofacial defects caused by factors, such as head injuries, cerebral tumors, ischemia, infections, or intracranial disorders, contribute to loss of bone tissues and the corresponding need for later reconstruction. ${ }^{1}$ Cranioplasty has been a preferred procedure in modern neurosurgery for the repair of bone defects using various materials, including bone and alloplastic materials. ${ }^{1,2}$ Cranioplasty is a critical procedure as skull integrity protects the brain. ${ }^{1,2}$ Cranial reconstruction also contributes to the preservation of the esthetic aspects of the head and restores an individual's quality of life. ${ }^{3}$

Several materials have been used for reconstruction of cranial defects. The ideal material for cranioplasty must be radiolucent, resistant to infection 
and biomechanical deformation, strong, nonconductive to heat or cold, can be fitted to defects with complete closure, inexpensive, and available for immediate use. ${ }^{4,5}$ Although various materials have been proposed, currently no available material meets these criteria. ${ }^{1,4}$

Autologous bone grafts have traditionally been considered the gold standard for cranial reconstruction ${ }^{6}$ given that bone is a natural substrate. ${ }^{78}$ Autologous bone grafts are associated with low cost and low risk and are preferred materials for small- and medium-sized defects. ${ }^{1,6}$ The disadvantages of autologous bone grafts include the limited quantity of material (as quality depends on the availability of graft donors), difficulty in shaping the graft, and increased morbidity and risk of complications, including infection and bone resorption. ${ }^{6,9}$

Alloplastic materials are alternatives to autologous bone grafts; these materials must possess biocompatibility, adequate mechanical resistance, malleability for esthetic purposes, and low risk of infection. Candidate materials include metals (titanium mesh), ceramics (hydroxyapatite and calcium phosphate) and polymers (polymethyl methacrylate [PMMA] or polyetheretherketone [PEEK]). ${ }^{10}$ Titanium features good mechanical and biological properties; however, it is expensive $\mathrm{e}^{3,11,12}$ and can result in infection. Titanium mesh generates artifacts in imaging tests and presents difficulty for adaption for soft tissue coverage. ${ }^{6}$

Similar to native bone tissue, PMMA offers strength and protection and has long been used in cranioplasty ${ }^{1,13}$ owing to its remarkable plasticity and long-term durability. PMMA is easy to shape, lightweight, inexpensive, and produces no visible artifacts in radiographic images. ${ }^{4,8,14}$ This material can also be applied during reconstruction and be prefabricated. ${ }^{8,11}$ However, despite these advantages, PMMA can cause damage to human cells. ${ }^{15,16}$ The primary factors responsible for this effect include residual monomers from polymerization. ${ }^{3}$ Processing type can also influence the complication rate of this material. ${ }^{17}$ The lack of porosity of PMMA can also interfere with osteoconduction and vascularization, compromising interactions with surrounding tissues. PMMA may be as susceptible or more prone to infection as autologous bone tissue.,18

To emphasize, cranioplasty material indications need to be based on scientific findings. Many reviews have evaluated the effects of various materials, including PMMA, that are used for cranioplasty. ${ }^{1,4,5,19,20}$ However, in most cases, these reviews included studies with indirect comparisons, that is, without comparison of different materials in the same included study. No systematic review specifically evaluated the influence of PMMA compared with other materials in terms of complication rates for cranioplasty.

Therefore, careful analysis of clinical studies should be performed through systematic review and metaanalysis to assess the influence of PMMA in comparison with autologous bone and titanium mesh in terms of complication rates. The null hypothesis states that no difference exists between the complication rates of PMMA compared with those of other materials.

\section{Methodology}

\section{Registration protocol}

This systematic review follows the structural pattern in the preferred reporting items for systematic reviews and meta-analyses checklist. ${ }^{13}$ The methods used in this systematic review were registered in the PROSPERO database (CRD42016042725).

\section{Eligibility criteria}

This analysis included randomized controlled trials (RCTs), prospective studies, retrospective studies, follow-up studies, and studies in English that evaluated the biological behavior of acrylic resin in craniofacial prostheses. Studies focusing only on mechanical and physical outcomes, in vitro studies, animal studies, clinical cases, and literature reviews were excluded.

The population, intervention, comparison, and outcome approach was used to address the question, "Do PMMA prostheses used in cranioplasty have complication rates similar to those of autologous bone or titanium mesh?" The population comprised patients who had undergone cranioplasty. Intervention involved the use of PMMA prostheses for cranioplasty. Comparison focused on the use of autologous bone or titanium mesh. The primary outcome was complication rates.

\section{Search strategy and information sources}

Two independent researchers (R.S.L. and J.R.S.M.) conducted an electronic search and selected studies 
that evaluated cranioplasty with different materials (PMMA compared with autologous bone graft and titanium mesh). Electronic searches of the selected databases (PubMed/MEDLINE, Web of Science, and Scopus) were conducted for articles published before March 2017. The following keywords were used: "acrylic resin" AND "maxillofacial prostheses" OR "acrylic resin" AND "cranioplasty" OR "acrylic resin" AND "maxillofacial" AND "prostheses" OR "acrylic resin" AND "head neck." To complement this search, a manual search was performed in journals, including Journal of Oral and Maxillofacial Surgery, Journal of Cranio-MaxilloFacial Surgery, International Journal of Maxillofacial Surgery, The Journal of Craniofacial Surgery, Journal of Oral Biology and Craniofacial Research, and Neurosurgery. Articles were selected according to eligibility criteria after title and abstract screening. Any disagreements between the researchers were resolved by a third researcher (S.L.D.M.), and consensus was reached through discussion.

\section{Data analysis}

Relevant information from the articles were collected by one of the authors (R.S.L.), and a second author (J.R.S.M.) verified the collected information. In case of disagreement between the first two authors, a third author (S.L.D.M.) conducted a careful analysis, and consensus was reached through discussion.

\section{Risk of bias and quality analysis of the included studies}

Two researchers (R.S.L. and J.R.S.M.) qualitatively analyzed the methodological quality of the selected studies using the Newcastle-Ottawa Scale (NOS) for cohort studies (non-RCTs); analysis is based on three major components: selection, comparability, and outcomes. In this quality scale, scores are represented by stars. A score of five or fewer stars represents a high risk of bias, whereas six or more stars (maximum of nine) are considered to indicate a low risk of bias. ${ }^{21}$

\section{Summary measures}

The dichotomous outcome measure was the occurrence of complications, as evaluated by risk ratio (RR) and its 95\% confidence interval (CI). $\mathrm{I}^{2}$ statistic was used to express the percentage of total variation across studies due to heterogeneity, with $25 \%$ corresponding to low heterogeneity, $50 \%$ to moderate, and $75 \%$ to high. ${ }^{22}$ A random effects or fixed effects model was used for analysis, depending on study heterogeneity. In cases of significant heterogeneity $(\mathrm{P}<0.10)$, a random effects model was used to assess the significance of treatment effects. If no significant heterogeneity was identified, analysis was performed using a fixed effects model..$^{14,15}$ Funnel plots (plots of effect size versus standard error) were also constructed. Asymmetry of a funnel plot may indicate publication bias or other biases related to the sample size; however, asymmetry may also represent a true relationship between the trial and effect size. ${ }^{14}$ Review Manager 5.3 (The Cochrane Library) was used to perform meta-analysis and create forest plots; $\mathrm{P}<$ 0.05 was considered significant.

\section{Additional analysis}

Kappa score was used to calculate the agreement between researchers during selection. Any disagreements were resolved by discussion and consensus among all authors.

\section{Results}

\section{Risk of bias assessment}

Mean score was 7 stars, and the lowest was 5 stars. Only one study ${ }^{3}$ showed the highest score (9 stars), indicating a low risk of bias (Table 1$){ }^{23}$

\section{Literature search}

A total of 1014 articles were obtained from the databases: 648 from PubMed/MEDLINE, 317 from Scopus, and 49 from Web of Science. After removing duplicate articles, a detailed review of titles and abstracts of the selected studies was performed. After applying the inclusion/exclusion criteria, 65 complete papers were selected for eligibility assessment. After reading the full texts of these articles, 11 studies ${ }^{1,2,4,5,12,16-21}$ were included in the final review. Details of the search strategy are presented in a flow diagram (Figure 1). Table 2 summarizes the contents of articles used for comparative analysis.

\section{Inter-investigator agreement}

Inter-examiner agreement (kappa) reached 0.94 for PubMed/MEDLINE, 0.89 for Scopus, and 1.00 for Web 
Table 1. Newcastle-Ottawa scale.

\begin{tabular}{|c|c|c|c|c|c|c|c|c|c|c|}
\hline \multirow[b]{2}{*}{ Studies } & \multicolumn{4}{|c|}{ Selection } & \multicolumn{2}{|c|}{ Comparability } & \multicolumn{3}{|c|}{ Outcome } & \multirow[b]{2}{*}{ Tota } \\
\hline & $\begin{array}{l}\text { Exposed } \\
\text { cohort }^{*}\end{array}$ & $\begin{array}{c}\text { Non } \\
\text { exposided } \\
\text { cohort }^{*}\end{array}$ & $\begin{array}{l}\text { Ascertainment } \\
\text { of exposure }\end{array}$ & $\begin{array}{c}\text { Outcome of } \\
\text { tinterest not } \\
\text { present } \\
\text { at start }\end{array}$ & Main factor & $\begin{array}{l}\text { Additional } \\
\text { factor }\end{array}$ & $\begin{array}{l}\text { Assessment } \\
\text { of outcome }\end{array}$ & $\begin{array}{c}\text { Follow-up } \\
\text { long } \\
\text { enough }\end{array}$ & $\begin{array}{c}\text { Adequacy of } \\
\text { follow-up }\end{array}$ & \\
\hline $\begin{array}{l}\text { Rosseto et al. } \\
2015^{17}\end{array}$ & 0 & • & - & $\bullet$ & - & 0 & $\bullet$ & $\bullet$ & $\bullet$ & 7 \\
\hline $\begin{array}{l}\text { Klinger et al. } \\
2014\end{array}$ & 0 & $\bullet$ & - & - & $\bullet$ & 0 & $\bullet$ & 0 & $\bullet$ & 6 \\
\hline $\begin{array}{l}\text { Bobinski et al. } \\
2013^{12}\end{array}$ & 0 & $\bullet$ & • & 0 & $\bullet$ & 0 & $\bullet$ & - & - & 6 \\
\hline $\begin{array}{l}\text { Al-Tamimi et al. } \\
2012^{5}\end{array}$ & 0 & - & - & $\bullet$ & $\bullet$ & 0 & - & $\bullet$ & • & 7 \\
\hline $\begin{array}{l}\text { Sahoo et al. } \\
2010^{1}\end{array}$ & $\bullet$ & • & • & $\bullet$ & $\bullet$ & - & $\bullet$ & $\bullet$ & - & 9 \\
\hline $\begin{array}{l}\text { Lee et al. } \\
2009^{7}\end{array}$ & $\bullet$ & - & - & - & $\bullet$ & 0 & - & - & - & 8 \\
\hline $\begin{array}{l}\text { Cheng et al. } \\
2008^{16}\end{array}$ & 0 & $\bullet$ & - & 0 & $\bullet$ & - & - & - & - & 7 \\
\hline $\begin{array}{l}\text { Matsuno et al. } \\
2006^{14}\end{array}$ & 0 & - & - & $\bullet$ & $\bullet$ & - & - & - & - & 8 \\
\hline $\begin{array}{l}\text { Josan et al. } \\
2005^{19}\end{array}$ & $\bullet$ & $\bullet$ & - & 0 & $\bullet$ & 0 & $\bullet$ & - & - & 7 \\
\hline $\begin{array}{l}\text { Bandyopadhyay } \\
\text { et al. } 2005\end{array}$ & 0 & - & - & 0 & $\bullet$ & 0 & $\bullet$ & 0 & $\bullet$ & 5 \\
\hline $\begin{array}{l}\text { Moreira-Gonzalez } \\
\text { et al. } 2003\end{array}$ & 0 & $\bullet$ & - & 0 & $\bullet$ & 0 & - & $\bullet$ & - & 6 \\
\hline
\end{tabular}

of Science. This value was calculated by evaluating the selected titles and abstracts that presented high levels of agreement among the reviewers under the kappa criterion. ${ }^{22}$

\section{Study description}

All studies centered on cranial implants and reported data on 1278 cranioplasties performed in 1256 patients (mean age: 34.14 years; $65.5 \%$ men). Nine studies were retrospective, and two were prospective. All 11 studies reported PMMA results and compared two or more materials. Autologous bone graft was the most commonly used material (408 cases); PMMA was used in 379 cases, titanium in 151, and ceramics in 10. Follow-up period was reported in nine papers ( $n=1003$ cases) and ranged from 63 days to 54.3 months. Indications for cranioplasty were not cited in one study $(\mathrm{n}=45)$. Trauma as an isolated factor was the most common indication ( $n=592$ cases), and non-traumatic events (including aneurysm, tumor, infection, and hemorrhage) were indications in 640 cases.
PMMA was one of the materials selected for cranioplasties in all 11 studies $(n=431$ cases, $38.7 \%$ ). ${ }^{1,2,45,12,16-21}$ In nine studies, autologous bone grafts were also used as treatment. Titanium was used in six studies. Other reported materials included hydroxyapatite ( $\mathrm{n}=40$ cases, $3.12 \%$ ), ceramics $(\mathrm{n}=17$ cases, $1.3 \%$ ), and titanium associated with PMMA ( $n=3$ cases, $0.23 \%$ ), which were each used in a single study.

\section{Complication rates}

Of the analyzed materials, autologous bone presented a complication rate of $17.44 \%$ (108), PMMA of $14.1 \%$ (61), titanium of $8.6 \%$ (13), ceramic of $5.88 \%$ (1), hydroxyapatite of $32.5 \%$ (13), and PMMA + titanium of $0 \%(0)$. Among all complications $(n=205)$, infection was the most prevalent $(113,55.1 \%)$, followed by hematoma $(36,17.5 \%)$, dehiscence $(17,8.2 \%)$, seroma $(9,4.4 \%)$, material displacement $(7,3.4 \%)$, thermal sensitivity $(2,1 \%)$, bone resorption $(2,1 \%)$, and edema $(1,0.5 \%)$. 

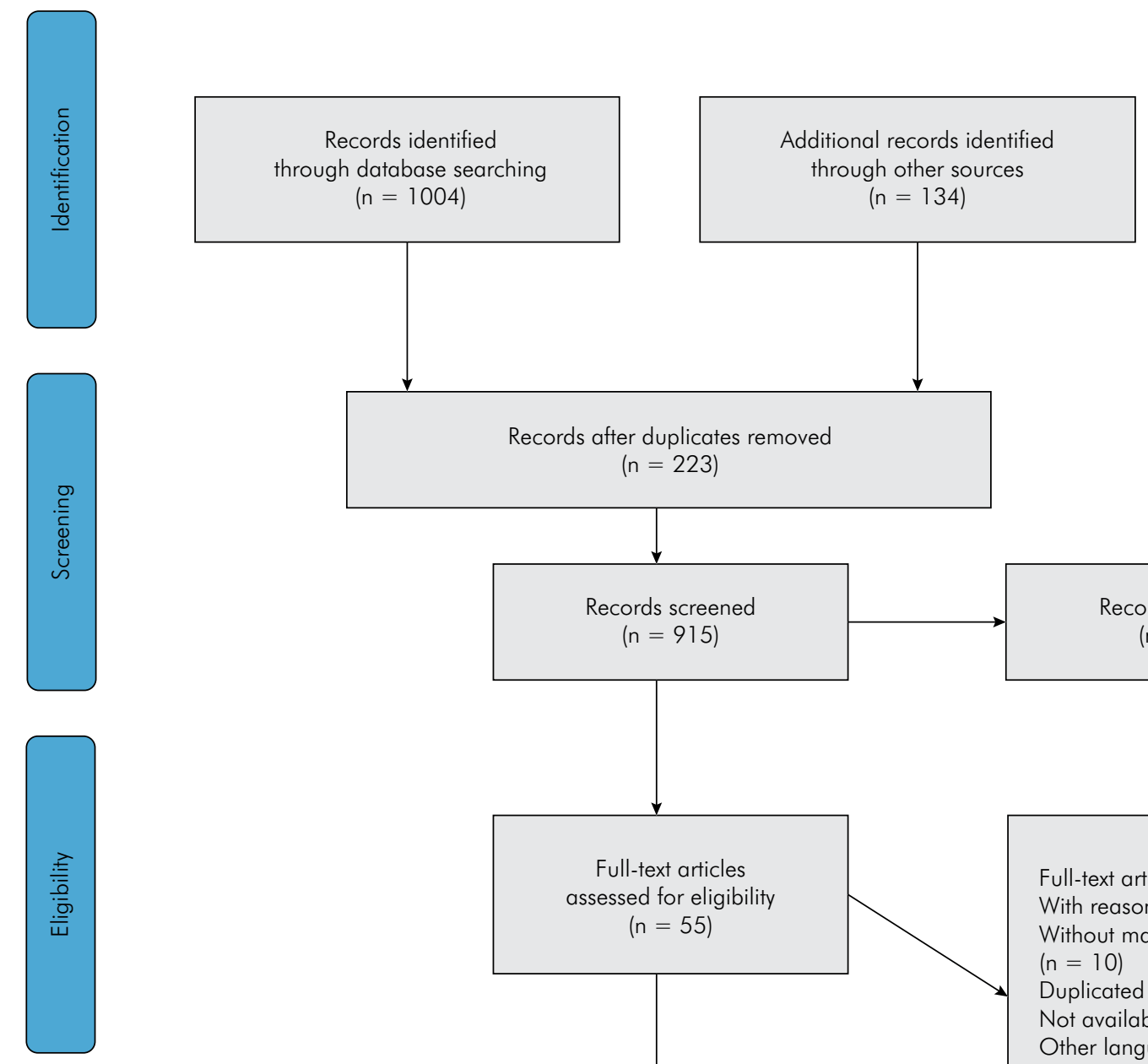

Records after duplicates removed

$$
(n=223)
$$
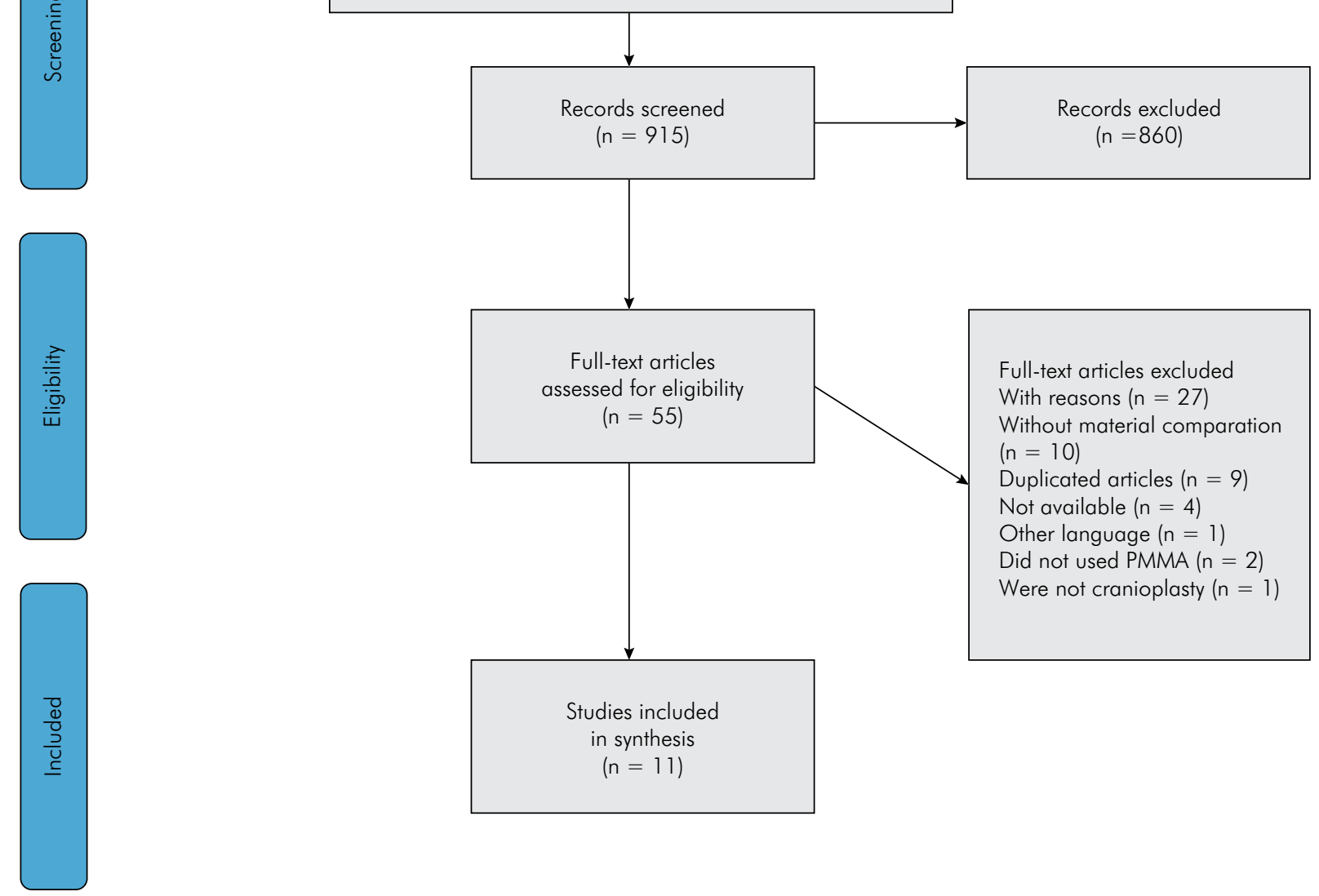

Studies included in synthesis $(\mathrm{n}=11)$

Figure 1. Flowchart of literature search.

Complication rates of PMMA and autologous bone were compared in nine studies. . $24,12,16-19,21$ In this analysis, a random effects model was used to compare the complication rates of materials (PMMA and autologous bone graft), as significant heterogeneity was observed $\left(\mathrm{p}<0.008 ; \mathrm{I}^{2}=61 \%\right)$. No significant difference was observed between PMMA and autologous bone for cranioplasty ( $p=0.94 ; R R, 0.98 ; 95 \% C I, 0.54-1.75 ;$ Figure 2).
A random effects model was used to compare the complication rates of PMMA and titanium mesh, as significant heterogeneity was observed $(\mathrm{p}<0.08$; $\mathrm{I}^{2}=60 \%$ ) in five studies. ${ }^{3,11,24-26}$ No significant difference was observed between the materials $(\mathrm{P}=0.38$; $\mathrm{RR}$, 1.59; 95\%CI, 0.57-4.48; Figure 3).

A sub-analysis was conducted to determine whether the reason for cranioplasty (trauma vs. non-trauma) 


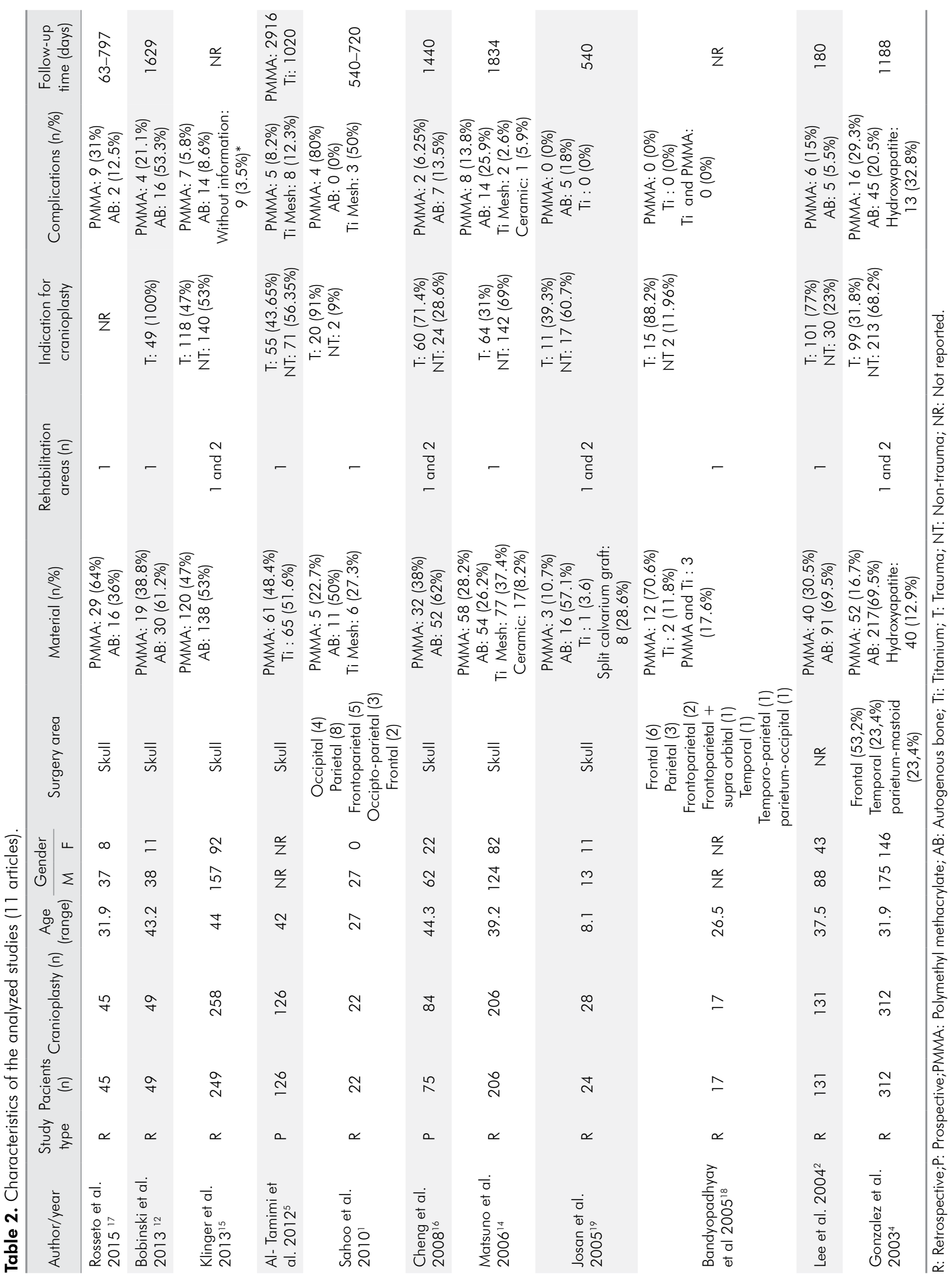




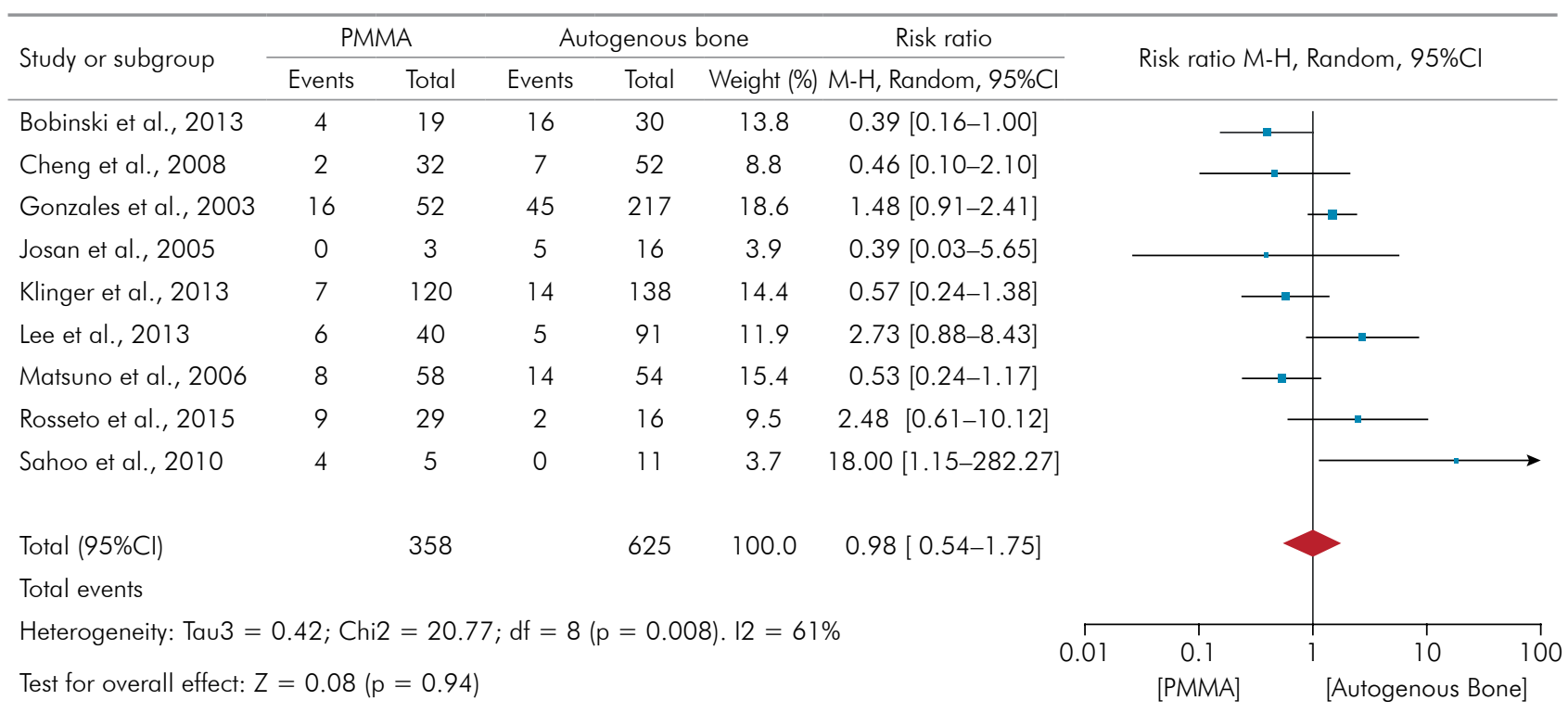

Figure 2. Forest plot: comparison between PMMA and autologous bone grafts with respect to complications.

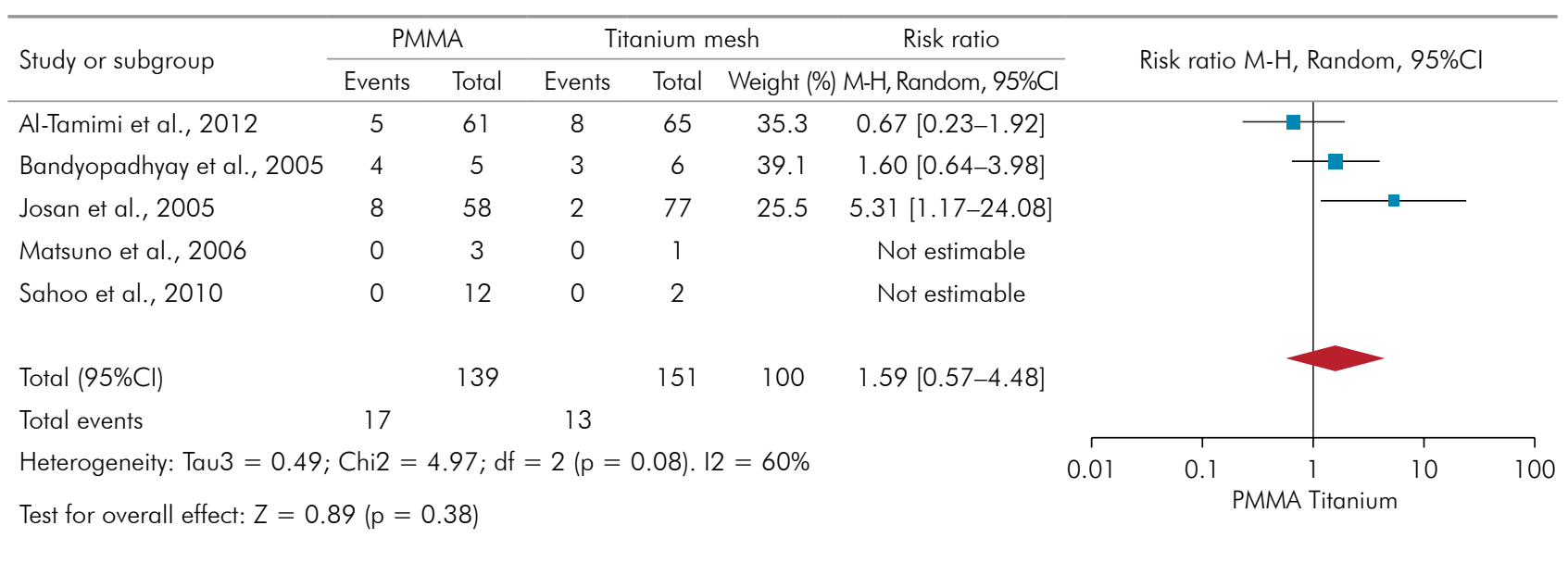

Figure 3. Forest plot: comparison between PMMA and titanium with respect to complications.

influences the complication rate of PMMA. A fixed effects model was used given the lack of significant heterogeneity $\left(\mathrm{p}=1.00 ; \mathrm{I}^{2}=0 \%\right)$. Data from three studies were compared, ${ }^{1,16,18}$ and no significant difference was observed ( $\mathrm{P}=0.91$; RR, 0.95; 95\%CI, 0.37-2.42; Figure 4).

The funnel plots of the studies included in analyses of complication rates of PMMA versus autologous bone and PMMA versus titanium mesh and etiology of trauma versus non-trauma showed symmetry, indicating the possible absence of publication bias (Figures 5 A, 5 B, and 5 C, respectively).

\section{Discussion}

Currently, alloplastic materials are considered alternatives for cranioplasty to autologous bone, particularly when considering a large skull area. ${ }^{1}$ Among the various alloplastic materials that can be used for cranioplasty, PMMA and PEEK have been considered favorable. ${ }^{1,6,27}$

A previous systematic review comparing the effects of PEEK with those of autologous bone and titanium mesh revealed no significant difference 


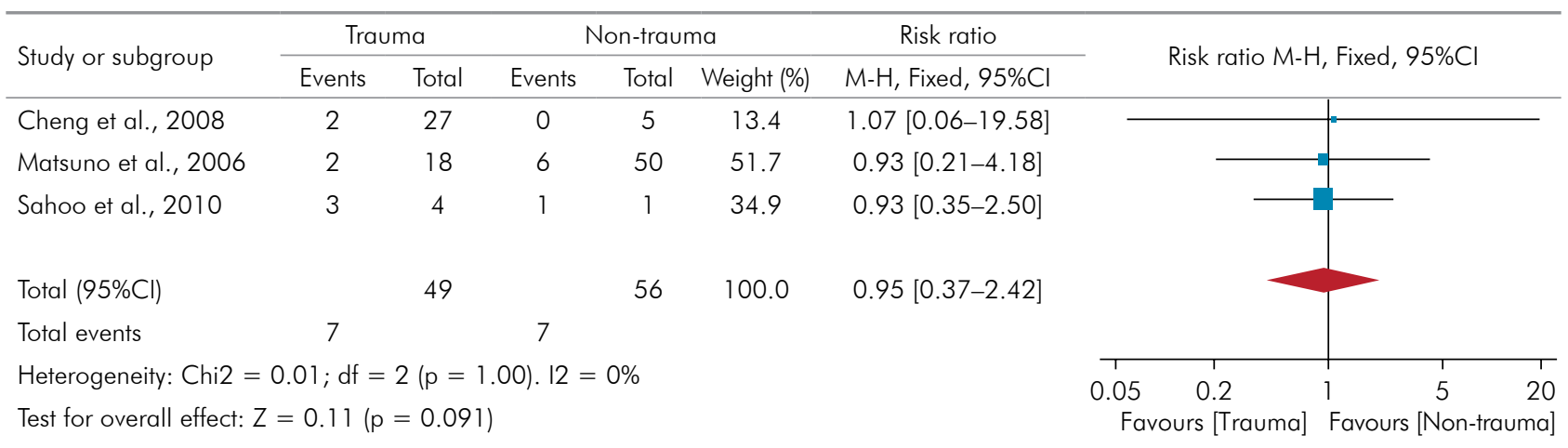

Figure 4. Forest plot: comparison of indication (trauma/non-trauma) and occurrence of complications when PMMA was used as the material of choice.

in complication rates. ${ }^{6}$ The current meta-analysis revealed no difference between the complication rates of PMMA and other materials (autologous bone and titanium mesh). Thus, the null hypothesis of this study was accepted. These results corroborate with those of other studies. ${ }^{28,29}$

Infection was the most prevalent complication (55.1\%). In several studies, $711,24-26,28,30-32$ infection may have occurred as a result of technical errors during surgery. This result may be related not only to the type of material but also to different risk factors in patients, such as hypertension and diabetes, ${ }^{20}$ systemic infection, lower hemoglobin levels, motor deficits, and the interval between craniotomy and cranioplasty. ${ }^{32}$

Only two studies evaluated the failure rate ${ }^{11,33}$ of cranioplasty material throughout a follow-up period. This condition explains why failure rate was not evaluated as an outcome in the present study. Bobinsk et al. ${ }^{33}$ reported better long-term survival for PMMA than for autologous bone (79.5 vs. 48.1 months; $p=0.035)$. Similarly, Al-Tamimi et al. ${ }^{11}$ observed longer survival for PMMA (135 months) than for titanium mesh (92 months) but reported no statistical significance.

No differences were observed in the complication rates between autologous bone and PMMA. However, Bobisnk et al. ${ }^{33}$ showed higher complication incidence level at autologous bone cranioplasty. Although autologous bone is considered the gold standard material for cranioplasty because of its biocompatibility and genetic compatibility, its indication could be limited to smaller and medium defects $\left(<75 \mathrm{~cm}^{2}\right)$.
Higher incidence of complications for autologous bone could be related to infections, which may lead to partial resorption of bone graft and implant detachment. ${ }^{1}$ Thus, the use of autologous bone tissue may be related to frequent complications of bone resorption, ${ }^{31,33,34,35}$ particularly when applied to large areas of skull defect $\left(>75 \mathrm{~cm}^{2}\right) .{ }^{36}$ Another factor that contributes to bone resorption is the method of bone storage because freeze-dried bone loses its vitality and undergoes unpredictable resorption. ${ }^{37}$

Relevant information about bone grafts, which ideally would be included in this manuscript but was not provided by the authors, includes the area of the cranium that required rehabilitation, graft type,, 711 , $24,25,26,28,30,31,32,33$ and area from which the donor graft was obtained. $7,11,24,26,28,30,31,32,33$

Alloplastic materials, such as PMMA, are considered good choice for patients who require secondary reconstruction with a custom-made CAD/ CAM device following a previous failed cranioplasty (contour deformity caused by significant bone graft resorption or implant/bone graft removal resulting from infection). ${ }^{1}$ In studies on patients requiring new surgery after infection or bone resorption, PMMA presented a lower risk of complications compared with other materials. ${ }^{25,28,31}$

Titanium mesh showed no differences in complications compared with PMMA. However, the cost of titanium prostheses is much higher, causing difficulty in acquiring the material in locations with financial constraints and presenting a major disadvantage. In addition to processing, titanium 

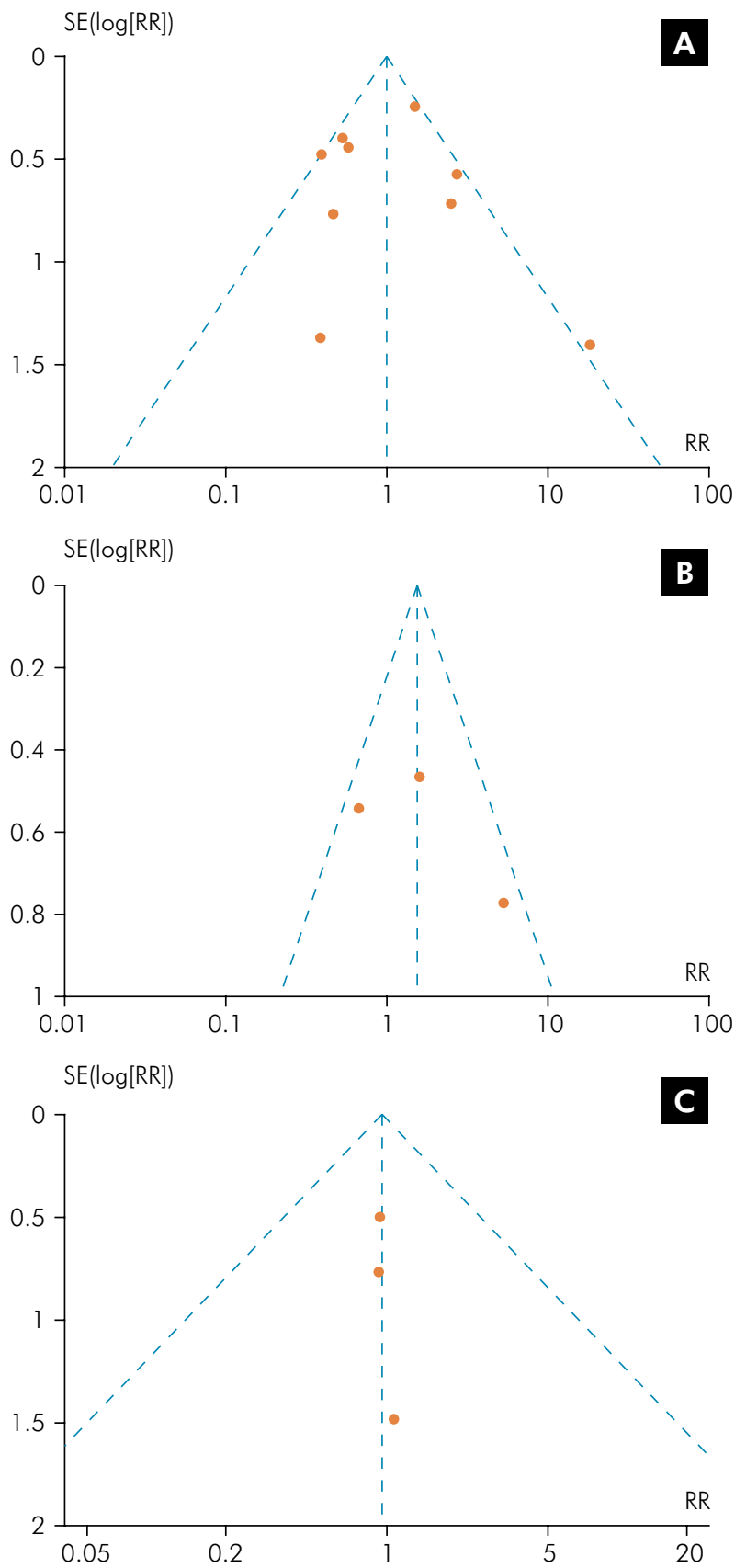

Figure 5. Funnel plot for the included studies. A: Complication rates of PMMA versus autologous bone grafts; $B$ : PMMA versus titanium mesh; C: Trauma versus non-trauma.

implants typically require advanced laboratory techniques. ${ }^{3}$ Another negative factor is that titanium can cause artifacts on magnetic resonance imaging; although slight and inert, they compromise the image. ${ }^{11}$ Biomechanically, titanium is a strong material and can withstand higher loads than PMMA, but PMMA tolerates forces better than bone tissue, generating acceptable neurocranial protection for fracture resistance. ${ }^{27}$

Although PMMA is considered a good choice for cranioplasty, it features some disadvantages, such as lack of adhesion to organic tissues, ${ }^{14,38}$ which increase the risk of infection and exposure of the material. ${ }^{3}$ Autogenous bone, by its nature, does not present this problem, and studies reported regeneration of the cortex of the defect area. ${ }^{39}$ Akan et al. ${ }^{12}$ observed that exothermic reaction of self-curing resin can result in damage to the surrounding tissues. The use of self-curing PMMA should be avoided as prosthesis are now manufactured in a preoperative stage and at an affordable cost. ${ }^{40}$ To minimize exothermic reaction in the surgical area, prosthesis could be previously manufactured in a prototype model aided by tomographic images. ${ }^{8}$ Another possibility is the use of thermal activation of PMMA. ${ }^{12}$ Although used with computed tomography and a prototype model, PMMA prostheses are much more affordable than titanium prostheses. The cost and decreased complexity of the technique can also reduce waiting time for surgery in the area to be rehabilitated.

Another disadvantage is the release of residual monomers by chemical activation of PMMA, which creates a possibility of tissue damage. ${ }^{3}$ The type of PMMA cure may influence the level of residual monomers present. Therefore, it would be interesting to compare different forms of polymerization of this material with the corresponding inflammatory responses. However, in some studies, the type of PMMA used is unclear; four studies used selfcuring $^{7,11,26,33}$ and two studies a thermoactivated. ${ }^{3,24}$

In several studies, trauma was the most common indication for cranioplasty. $3,724,31$ This observation accords with the age of individuals and the condition that most patients were men, which are characteristics of people at higher risk of automobile and other accidents. ${ }^{41}$ In this study, for PMMA, no statistical relationship was observed between the indication for cranioplasty and infection outcome. ${ }^{3,26,29,31,41}$ This result suggests that indication for cranioplasty is indirectly related to the probability of infection, which is related to individual systemic health, as previously reported. However, the small number 
of studies and patients in this analysis could have resulted in bias in these results.

Other materials, such as hydroxyapatite, ceramics, and PMMA + titanium, have also been used in the analyzed studies. ${ }^{26}$ We excluded these materials in the meta-analysis, as each was only used in one study. An analysis would be interesting, as materials such as ceramics possess the advantage of biocompatibility with human tissues. ${ }^{42}$

Compared with other alloplastic materials, PMMA is the least expensive and features satisfactory characteristics for cranioplasty. However, these alloplastic materials are not indicated for pediatric patients because of incompatibility to accommodate bone growth of cranial skeleton. ${ }^{1,18}$ The optimal material for cranioplasty in pediatric patients should be considered in future research. ${ }^{1}$

Considering these results and in agreement with literature, the choice of cranioplasty materials may be related to the preference of surgeons for the material used. ${ }^{1}$ Other alternatives for reducing complication rates, such as incorporation of antibiotics into the restorative material, may also be used. ${ }^{43}$ In addition, the approach of determining treatment by planning conformation and fixation of cranial prosthesis using finite element analysis for each isolated case was shown to be effective through the low complication rates presented. ${ }^{27}$

In this systematic review, the included studies reported no rates of specific types of complications (infection, hematoma, dehiscence, bone resorption, thermal sensitivity, and material displacement) according to the material used for cranioplasty, rendering the specific meta-analysis for each type of complication impossible. Another limitation was the lack of RCTs on the subject; only retrospective and prospective studies were used. For this reason, NOS was used to analyze the risk of bias because it is the most used instrument for non-RCTs. ${ }^{21}$ This scale includes three evaluation criteria: selection, comparability, and outcomes. Despite only one article reported the highest score ( 9 stars $=$ low risk of bias), mean across the included studies reached 7 stars. However, for some studies, the sample selection method was unclear, with no other comparations factors excluding the main comparation. This highlights the need for controlled studies on this subject.

The present findings should be cautiously interpreted. All included studies were retrospective and prospective, reducing the level of evidence because of the possible presence of uncontrolled confounding factors. A large variation was also between the follow-up periods of the included studies, and this observation is another limitation of this review. Further studies (preferably RCTs) with longer follow-up periods are recommended to investigate the influence of PMMA in cranioplasty and determine its likely effects.

\section{Conclusions}

This meta-analysis indicates that complication rates of PMMA in cranioplasty show no statistical difference from those of autologous bone grafts or titanium.

\section{Acknowledgments}

We thank Dr. Pablo Maricevich, plastic surgeon at Recife's Restoration Hospital. Recife, Pernambuco, Brazil, for his help with some elucidations.

\section{References}

1. Zanotti B, Zingaretti N, Verlicchi A, Robiony M, Alfieri A, Parodi PC. Cranioplasty: review of materials. J Craniofac Surg. 2016 Nov;27(8):2061-72. https://doi.org/10.1097/SCS.0000000000003025

2. Andrabi SM, Sarmast AH, Kirmani AR, Bhat AR.

Cranioplasty: Indications, procedures, and outcome: an institutional experience. Surg Neurol Int. 2017 May;8(1):91. https://doi.org/10.4103/sni.sni_45_17
3. Sahoo N, Roy ID, Desai AP, Gupta V. Comparative evaluation of autogenous calvarial bone graft and alloplastic materials for secondary reconstruction of cranial defects. J Craniofac Surg. 2010 Jan;21(1):79-82. https://doi.org/10.1097/SCS.0b013e3181c3ba58

4. Aydin S, Kucukyuruk B, Abuzayed B, Aydin S, Sanus GZ. Cranioplasty: review of materials and techniques. J Neurosci Rural Pract. 2011 Jul;2(2):162-7. https://doi.org/10.4103/0976-3147.83584 
5. Shah AM, Jung $H$, Skirboll S. Materials used in cranioplasty: a history and analysis. Neurosurg Focus. 2014 Apr;36(4):E19. https://doi.org/10.3171/2014.2.FOCUS13561

6. Punchak M, Chung LK, Lagman C, Bui TT, Lazareff J, Rezzadeh $\mathrm{K}$ et al. Outcomes following polyetheretherketone (PEEK) cranioplasty: systematic review and meta-analysis. J Clin Neurosci. 2017 Jul;41:30-5. https://doi.org/10.1016/i.jocn.2017.03.028

7. Lee SC, Wu CT, Lee ST, Chen PJ. Cranioplasty using polymethyl methacrylate prostheses. J Clin Neurosci. 2009 Jan;16(1):56-63. https://doi.org/10.1016/i.jocn.2008.04.001

8. Turgut G, Özkaya Ö, Kayali MU. Computer-aided design and manufacture and rapid prototyped polymethylmethacrylate reconstruction. J Craniofac Surg. 2012 May;23(3):770-3. https://doi.org/10.1097/SCS.0b013e31824dbcaf

9. Alonso-Rodriguez E, Cebrián JL, Nieto MJ, Del Castillo JL, Hernández-Godoy J, Burgueño M. Polyetheretherketone custom-made implants for craniofacial defects: report of 14 cases and review of the literature. J Craniomaxillofac Surg. 2015 Sep;43(7):1232-8. https://doi.org/10.1016/i.jcms.2015.04.028

10. Goldstein JA, Paliga JT, Bartlett SP. Cranioplasty: indications and advances. Curr Opin Otolaryngol Head Neck Surg. 2013 Aug;21(4):400-9. https://doi.org/10.1097/MO0.0b013e328363003e

11. Al-Tamimi YZ, Sinha P, Trivedi M, Robson C, Al-Musawi TA, Hossain $\mathrm{N}$ et al. Comparison of acrylic and titanium cranioplasty. Br J Neurosurg. 2012 Aug;26(4):510-3. https://doi.org/10.3109/02688697.2011.633640

12. Akan M, Karaca M, Eker G, Karanfil H, Aköz T. Is polymethylmethacrylate reliable and practical in full-thickness cranial defect reconstructions? J Craniofac Surg. 2011 Jul;22(4):1236-9. https://doi.org/10.1097/SCS.0b013e31821c0f34

13. Muñoz XM, Bonardi JP, Silva LF, Reis EN, Pires WR, Fabris AL et al. Cranioplasty With Poly-Methyl Methacrylate Resin. J Craniofac Surg. 2017 Jan;28(1):294-5. https://doi.org/10.1097/SCS.0000000000003226

14. Jaberi J, Gambrell K, Tiwana P, Madden C, Finn R. Longterm clinical outcome analysis of poly-methyl-methacrylate cranioplasty for large skull defects. J Oral Maxillofac Surg. 2013 Feb;71(2):e81-8. https://doi.org/10.1016/i.joms.2012.09.023

15. Ata SO, Yavuzyilmaz $\mathrm{H}$. In vitro comparison of the cytotoxicity of acetal resin, heat-polymerized resin, and auto-polymerized resin as denture base materials. J Biomed Mater Res B Appl Biomater. 2009 Nov;91(2):905-9. https://doi.org/10.1002/jbm.b.31473

16. Barron DJ, Schuster GS, Caughman GB, Lefebvre CA. Biocompatibility of visible light-polymerized denture base resins. Int J Prosthodont. 1993 Sep-Oct;6(5):495-501.

17. Bural C, Aktaş E, Deniz G, Ünlüçerçi Y, Bayraktar G. Effect of leaching residual methyl methacrylate concentrations on in vitro cytotoxicity of heat polymerized denture base acrylic resin processed with different polymerization cycles. J Appl Oral Sci. 2011 Aug;19(4):306-12. https://doi.org/10.1590/S1678-77572011005000002
18. Goiato MC, Anchieta RB, Pita MS, dos Santos DM. Reconstruction of skull defects: currently available materials. J Craniofac Surg. 2009 Sep;20(5):1512-8. https://doi.org/10.1097/SCS.0b013e3181b09b9a

19. Khader BA, Towler MR. Materials and techniques used in cranioplasty fixation: A review. Mater Sci Eng C. 2016 Sep;66:315-22. https://doi.org/10.1016/i.msec.2016.04.101

20. Piitulainen JM, Kauko T, Aitasalo KM, Vuorinen V, Vallittu PK, Posti JP. Outcomes of cranioplasty with synthetic materials and autologous bone grafts. World Neurosurg. 2015 May;83(5):708-14. https://doi.org/10.1016/j.wneu.2015.01.014

21. Wells GA, Shea B, O'Connell D, Peterson J, Welch V, Losos $M$ et al. The Newcastle-Ottawa Scale (NOS) for assessing the quality of nonrandomised studies in meta-analyses. Ottawa: The Ottawa Hospitala Research Institute, 2017 [cited 2017 April 4]. Available from: http://www.ohri.ca/ programs/clinical_epidemiology/oxford.asp

22. Chrcanovic BR, Albrektsson T, Wennerberg A. Reasons for failures of oral implants. J Oral Rehabil. 2014 Jun;41(6):443-76. https://doi.org/10.1111/joor.12157

23. Huang YH, Lee TC, Yang KY, Liao CC. Is timing of cranioplasty following posttraumatic craniectomy related to neurological outcome? Int J Surg. 2013;11(9):886-90. https://doi.org/10.1016/j.ijsu.2013.07.013

24. Bandyopadhyay TK, Thapliyal GK, Dubey AK. Reconstruction of cranial defects in Armed Forces personnel: our experience. Med J Armed Forces India. 2005 Jan;61(1):36-40. https://doi.org/10.1016/S0377-1237(05)80116-9

25. Josan VA, Sgouros S, Walsh AR, Dover MS, Nishikawa $\mathrm{H}$, Hockley AD. Cranioplasty in children. Childs Nerv Syst. 2005 Mar;21(3):200-4. https://doi.org/10.1007/s00381-004-1068-2

26. Matsuno A, Tanaka H, Iwamuro H, Takanashi S, Miyawaki S, Nakashima M et al. Analyses of the factors influencing bone graft infection after delayed cranioplasty. Acta Neurochir (Wien). 2006 May;148(5):535-40. https://doi.org/10.1007/s00701-006-0740-6

27. Ridwan-Pramana A, Marcián P, Borák L, Narra N, Forouzanfar T, Wolff J. Finite element analysis of 6 large PMMA skull reconstructions: A multi-criteria evaluation approach. PLoS One. 2017 Jun;12(6):e0179325. https://doi.org/10.1371/journal.pone.0179325

28. Klinger DR, Madden C, Beshay J, White J, Gambrell K, Rickert K. Autologous and acrylic cranioplasty: a review of 10 years and 258 cases. World Neurosurg. 2014 Sep-Oct;82(3-4):e525-30. https://doi.org/10.1016/i.wneu.2013.08.005

29. Krause-Titz UR, Warneke N, Freitag-Wolf S, Barth H, Mehdorn $H M$. Factors influencing the outcome (GOS) in reconstructive cranioplasty. Neurosurg Rev. 2016 Jan;39(1):133-9. https://doi.org/10.1007/s10143-015-0678-3

30. Moreira-Gonzalez A, Jackson IT, Miyawaki T, Barakat K, DiNick V. Clinical outcome in cranioplasty: critical review in longterm follow-up. J Craniofac Surg. 2003 Mar;14(2):144-53. https://doi.org/10.1097/00001665-200303000-00003 
- Complications with PMMA compared with other materials used in cranioplasty: a systematic review and meta-analysis

31. Cheng YK, Weng HH, Yang JT, Lee MH, Wang TC, Chang $\mathrm{CN}$. Factors affecting graft infection after cranioplasty. J Clin Neurosci. 2008 Oct;15(10):1115-9. https://doi.org/10.1016/i.jocn.2007.09.022

32. Rosseto RS, Giannetti AV, de Souza Filho LD, Faleiro RM. Risk Factors for Graft Infection After Cranioplasty in Patients with Large Hemicranial Bony Defects. World Neurosurg. 2015 Aug;84(2):431-7. https://doi.org/10.1016/j.wneu.2015.03.045

33. Bobinski L, Koskinen LO, Lindvall P. Complications following cranioplasty using autologous bone or polymethylmethacrylate_-retrospective experience from a single center. Clin Neurol Neurosurg. 2013 Sep;115(9):1788-91. https://doi.org/10.1016/i.clineuro.2013.04.013

34. Rotaru H, Stan H, Florian IS, Schumacher R, Park YT, Kim SG et al. Cranioplasty with custom-made implants: analyzing the cases of 10 patients. J Oral Maxillofac Surg. 2012 Feb;70(2):e169-76. https://doi.org/10.1016/i.joms.2011.09.036

35. Chiarini L, Figurelli S, Pollastri G, Torcia E, Ferrari F, Albanese $\mathrm{M}$ et al. Cranioplasty using acrylic material: a new technical procedure. J Craniomaxillofac Surg. 2004 Feb;32(1):5-9. https://doi.org/10.1016/i.jcms.2003.08.005

36. Grant GA, Jolley M, Ellenbogen RG, Roberts TS, Gruss JR, Loeser JD. Failure of autologous boneassisted cranioplasty following decompressive craniectomy in children and adolescents. J Neurosurg 2004;100(2 Suppl Pediatrics):163-8. https://doi.org/10.3171/ped.2004.100.2.0163
37. Kumar NG, Rangarajan H, Shourie P. Cranioplasty of Hemispherical Defects Using High Impact Methylmethacrylic Plate. J Craniofac Surg. 2015 Sep;26(6):1882-6. https://doi.org/10.1097/SCS.0000000000002006

38. Manson PN, Crawley WA, Hoopes JE. Frontal cranioplasty: risk factors and choice of cranial vault reconstructive material. Plast Reconstr Surg. 1986 Jun;77(6):888-904. https://doi.org/10.1097/00006534-198606000-00003

39. Lee C, Antonyshyn OM, Forrest CR. Cranioplasty: indications, technique, and early results of autogenous split skull cranial vault reconstruction. J Craniomaxillofac Surg. 1995 Jun;23(3):133-42. https://doi.org/10.1016/S1010-5182(05)80001-0

40. Firtell DN, Grisius RJ. Cranioplasty of the difficult frontal region. J Prosthet Dent. 1981 Oct;46(4):425-9. https://doi.org/10.1016/0022-3913(81)90452-2

41. Wulkan M, Parreira Junior JG, Botter DA. [Epidemiology of facial trauma]. Rev Assoc Med Bras (1992). 2005 Sep-Oct;51(5):290-5. Portuguese. https://doi.org/10.1590/S0104-42302005000500022

42. Chen YW, Moussi J, Drury JL, Wataha JC. Zirconia in biomedical applications. Expert Rev Med Devices. 2016 Oct;13(10):945-63. https://doi.org/10.1080/17434440.2016.1230017

43. Worm PV, Nascimento TL, Nicola FC, Sanches EF, Moreira CFS, Rogério LP et al. Polymethylmethacrylate imbedded with antibiotics cranioplasty: an infection solution for moderate and large defects reconstruction? Surg Neurol Int. 2016 Nov;7(29 Suppl 28):S746-51. https://doi.org/10.4103/2152-7806.193725 